\title{
MONITORING THE ANTIBACTERIAL ACTIVITY OF HIBISCUS SABDARIFFA EXTRACTS
}

\author{
Magda, PANAITESCU ${ }^{1}$, Ecaterina LENGYEL ${ }^{2}$ \\ ${ }^{1}$ Univesidad ”Latina" de Panama, Panama, Rep. de Panama, e-mail: mpanaitescu@ulatina.edu.pa \\ ${ }_{2}^{2}$, Lucian Blaga” University of Sibiu, Sibiu, Romania, e-mail: ecaterina.lengyel@ulbsibiu.ro
}

\begin{abstract}
This paper focuses on studying the antibacterial effect of Hibiscus sabdariffa extracts, a plant known in traditional medicine for its beneficial effects on the body. Hibiscus sabdariffa extracts were done in pure water, 50\% ethyl alcohol, and $96 \%$ ethyl alcohol; the concentrations used to determine antibacterial activity were 1:1, 1:5, 1:10, 1:25, 1:50, noted cu 1, 2, 3, 4, 5. The antibacterial effect of the extracts was tested using the impregnated disk-diffusion method on bacteria Escherichia coli ATCC 25922, Salmonella typhimurium ATCC 14028, Enterobacter clocae ATCC 13047, Klepsiella pneumoniae ATCC 13833, Staphylococcus aureus ATCC 29213, Yersinia enterocolitica ATCC 9610. We ascertained that the most efficient extracts were those obtained using 96\% ethyl alcohol, 1:1 concentration on Escherichia coli ATCC 25922 and Enterobacter clocae ATCC 13047 strains, where the inhibitory action presented average values between $5.43 \mathrm{~mm}$ and $3.43 \mathrm{~mm}$. In the case of Klepsiella pneumoniae ATCC 13833 and Yersinia enterocolitica ATCC 9610 strains, the extracts recorded minimum or zero values. The antibacterial activity of Hibiscus sabdariffa depended on their concentration, on the solvent used, as well as on the resistance of the bacteria under study to the bioactive compounds in them.
\end{abstract}

Keywords: Hibiscus sabdariffa extracts, bacterial strains, antibacterial activity

\section{INTRODUCTION}

Hibiscus sabdariffa is one of those plants that are often found in traditional medicine, which means that it contains bioactive compounds has been verified over time. Their pharmacological, toxicological qualities, as well as their chemical composition have been intensely studied over the last period, which shows an ever-increasing interest in the features of plants in anthropic areas. Originating in tropical and subtropical areas, this plant has adapted to the most diverse places in the world, appearing in Asia (China, Thailand), Africa (Senegal, Egypt, Mali), Central America (Mexico, Jamaica, Panama), and even Europe (Da Costa Roca et al., 2014, Mohamed et al., 2012). People use it both as an ornamental plant, as well as in their diet, as tea, tinctures or tonic drinks, as it contains fibres and organic compounds ( $\mathrm{Da}$ Costa Roca et al. 2014). Up to date, studies have shown that they are rich in anthocyanins, flavonoids, vitamins, or microelements (Allarcon et al., 2012, Peng et al., 2011, Williamson et al., 2009, Yang et al., 2010). The genus is diverse, including over 300 species growing in all parts of the world which record temperatures above $20^{\circ} \mathrm{C}$. The chemical composition of the plants (leaves, flowers, seeds) leads to beneficial effects when consumed both as medicine, as well as part of the diet. As a medicine, the plant has beneficial effects on arterial pressure, contributes to a more rapid healing of wounds, in the form of tea, it is diuretic, antidiabetic, antidepressant, it solves a series of genital issues, playing a role in cholesterol stability, and is anticancerogenic (BeltranDebold et al., 2010, Frank et al., 2012, Wang et al., 2000, Dikel et al., 2007, Lin et al., 2012, Gosain et al., 2010). In the field of food, the plant is used in bioactive drinks, fermented drinks, in spices, and as a coffee substitute in some countries (Ploto et al. 2004, Okoro et al. 2007, Gaya et al. 2007, Kumar et al. 2013). The nutritional values of the plant differ according to the variety, the ecological or the growth pedoclimatic conditions, but, regardless of the area, we identified carbohydrates, reaching values between $9 \mathrm{~g} / 100 \mathrm{~g}$ and $12 \mathrm{~g} / 100 \mathrm{~g}$, proteins $(1.9 \mathrm{~g} / 100 \mathrm{~g}-3.3 \mathrm{~g} / 100 \mathrm{~g})$, fats $(0.1 \mathrm{~g} / 100 \mathrm{~g}-0.3 \mathrm{~g} / 100 \mathrm{~g})$, and fibres $(2.3 \mathrm{~g} / 100 \mathrm{~g}-3.4 \mathrm{~g} / 100 \mathrm{~g})$ (Ismail et al., 2008). Its antimicrobial activity derives from the frequent use of extracts in traditional medicine in order to heal bacterial infections, especially those caused by gram-negative bacteria (Afolabi et al., 2008, Chao 2008, Fullerton et al., 2011).

\section{MATERIALS AND METHODS}

$100 \mathrm{~g}$ dry Hibiscus sabdariffa flowers, $1 \mathrm{~L}$ pure water (A)

$100 \mathrm{~g}$ dry Hibiscus sabdariffa flowers, ethanol 50\% f.a. (B)

$100 \mathrm{~g}$ dry Hibiscus sabdariffa flowers, 1 L ethanol 96\% f.a. (C)

Bacteria: Escherichia coli ATCC 25922, Salmonella typhimurium ATCC 14028, Enterobacter clocae ATCC 13047, Klepsiella pneumoniae ATCC 13833, Staphylococcus aureus ATCC 29213, Yersinia enterocolitica ATCC 9610. The strains were activated according to the producer's recommendations; the number of viable cells was established to be $10 \% \mathrm{~mL}$.

$6 \mathrm{~mm}$ diameter sterile paper filter disks

Blood Agar growth media recommended for cultivating fastdeveloping pathogenic bacteria, poured into $9 \mathrm{~mm}$ Petri31 
dishes (12/strain).

Hibiscus sabdariffa flowers underwent a 10-day extraction at $15^{\circ} \mathrm{C}$. The extract obtained was separated through centrifugation, dried up, then diluted with pure water in $1: 1$, $1: 5,1: 10,1: 25,1: 50$ concentrations (noted cu 1, 2, 3, 4, 5), then underwent microbiological tests.

The work method consists of placing a thin layer of the reference strain (Escherichia coli ATCC 25922, Salmonella typhimurium ATCC 14028, Enterobacter clocae ATCC 13047, Klepsiella pneumoniae ATCC 13833, Staphylococcus aureus ATCC 29213, Yersinia enterocolitica ATCC 9610) on the Blood Agar growth medium and applying three disks on its surface. On each disk, you drop $5 \mu \mathrm{L}$ of extract, putting down the rime (A, $\mathrm{B}$, or $\mathrm{C}$, and the concentration of the extract). The dishes are incubated at $37^{\circ} \mathrm{C}$ for 48 hours, then measuring the inhibition area of the extract. Then, you calculate the arithmetic mean of the values obtained for each strain, respectively for each extract, the final results characterizing their efficiency.

\section{RESULTS AND DISCUSSIONS}

As shown in Table 1, the inhibition of the reference strain development reaches between 0 and $5.43 \mathrm{~mm}$, depending on the concentration of the extract, the strain, and the extraction type. In the case of Escherichia coli ATCC 25922, the 1:50 concentration was unfavourable to its development; nevertheless, we did obtain important results when using extract C (in 96\% ethanol), at a 1:1 concentration. We found increasing values of the inhibition area when using extraction in $96 \%$ ethanol, $1: 1$ concentration.

Bacterial strains
Escherichia coli
ATCC 25922

Salmonella
typhimurium ATCC
14028

Enterobacter clocae ATCC 13047

Klepsiella pneumoniae ATCC 13833
$3,12 \pm 0,21$
$2,31 \pm 0,15$
$1,59 \pm 0,12$
$0,19 \pm 0,02$
$0,1 \pm 0,3$

$1,12 \pm 0,02$

$1,02 \pm 0,03$

$-$

$-$
4

5
In the case of the strain Salmonella typhimurium ATCC 14028, the inhibition area is lower compared to those found in that of the strain Escherichia coli ATCC 25922, so their average is under $2.83 \mathrm{~mm}$. The same tendency applies to extract C, 1:1 concentration. In the case of this strain, extract concentrations 4 and 5 were not inhibitory, regardless of the extraction type (A, B, or C).

The strain Enterobacter clocae ATCC 13047 is especially sensitive if the extracts have a 1:1 concentration. In all the version used, we observed and measured the inhibition area, recording average values between $0.1 \mathrm{~mm}$ and $3.43 \mathrm{~mm}$. Watery extracts presented the lowest values, between $0.1 \mathrm{~mm}$ and $3.12 \mathrm{~mm}$. Alcoholic extracts $\mathrm{B}$ and $\mathrm{C}$ showed values between $0.24 \mathrm{~mm}$ and $3.42 \mathrm{~mm}$, respectively $0.31 \mathrm{~mm}$ and $3.43 \mathrm{~mm}$. Maximum average values obtained $(\mathrm{C} / 1)$ are close to those obtained in the case of strain Escherichia coli ATCC 25922 version $\mathrm{A} / 1$.

Table 1. Average inhibition values $(\mathrm{mm})$ of the development of the reference strains Escherichia coli ATCC 25922, Salmonella typhimurium ATCC 14028, Enterobacter clocae ATCC 13047, Klepsiella pneumoniae ATCC 13833, Staphylococcus aureus ATCC 29213, Yersinia enterocolitica ATCC 9610 related to extraction type (100 g dry Hibiscus sabdariffa flowers, $1 \mathrm{~L}$ pure water (A), $100 \mathrm{~g}$ dry Hibiscus sabdariffa flowers, 1L ethanol 50\% f.a. (B), $100 \mathrm{~g}$ dry Hibiscus sabdariffa flowers, $1 \mathrm{~L}$ ethanol $96 \%$ f.a. (C) at 1:1, 1:5, 1:10, 1:25, 1:50 extract concentrations; noted $1,2,3,4,5$ )

\section{Type of extracts}

\section{concentrations}

A

$3,02 \pm 0,31$

$2,12 \pm 0,05$

$1,89 \pm 0,11$

$0,14 \pm 0,03$

U.M.

B

$\mathrm{mm}$

$\begin{array}{rr}\text { B } & \text { U.M } \\ & \mathrm{mm} \\ 3,82 \pm 0,25 & \\ 2,97 \pm 0,03 & \\ 2,01 \pm 0,13 & \\ 0,19 \pm 0,07 & \\ - & \end{array}$

$\begin{array}{lr}\text { U.M. } & \text { C } \\ \text { mm } & \\ & 5,43 \pm 0,21 \\ & 4,97 \pm 0,13 \\ & 2,35 \pm 0,22 \\ & 0,24 \pm 0,02\end{array}$

U.M.

$\mathrm{mm}$
$2,83 \pm 0,01$

$2,07 \pm 0,03$

$1,31 \pm 0,02$

$1,02 \pm 0,01$

$0,39 \pm 0,11$

$1,17 \pm 0,02$

$1,01 \pm 0,13$

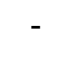

$3,43 \pm 0,23$

$2,97 \pm 0,15$

$2,55 \pm 0,26$

$0,44 \pm 0,05$

$0,31 \pm 0,02$

$3,22 \pm 0,45$
$2,77 \pm 0,13$
$2,11 \pm 0,16$
$0,31 \pm 0,07$
$0,24 \pm 0,05$

$1,83 \pm 0,02$

$1,32 \pm 0,02$

$1,47 \pm 0,03$

$1,15 \pm 0,02$
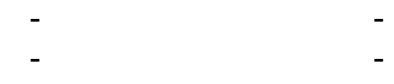

$3,42 \pm 0,01$

$4,83 \pm 0,01$ 


Yersinia
$\begin{aligned} & 2 \\ & 4\end{aligned}$
5
enterocolitica ATCC
9610
2
3
4

Looking at the results obtained in the case of strain Klepsiella pneumoniae ATCC 13833, we found that Hibiscus sabdariffa extracts are only enough in concentrations 1 and 2 and for all types of extracts. The resulting average values fit under 2 , meaning we can appreciate that the inhibitory effect is low.

In the case of the Staphylococcus aureus ATCC 29213 strain, average inhibition areas fall between $3.12 \mathrm{~mm}$ and $4.83 \mathrm{~mm}$ (1), between $2.42 \mathrm{~mm}$ and $2.99 \mathrm{~mm}$ for extract concentration 2 , and between $0.09 \mathrm{~mm}$ and $1.81 \mathrm{~mm}$ for extract concentration 3 . No favourable results were obtained in the case of extract A: its inhibition area at 1:25 and 1:50 concentration was 0 .

In the case of the strain Yersinia enterocolitica ATCC 9610, we only obtained results in the case of a maximum 1:1 concentration of Hibiscus sabdariffa extract obtained through 96\% ethyl alcohol maceration (C).

\section{CONCLUSIONS}

The research proved that Hibiscus sabdariffa extracts show an antibacterial activity, that is directly connected to the species under study, as well as to other factors, such as the concentration of the extract used and the way in which bioactive compounds are extracted. Extracts in $96 \%$ alcohol contained a higher amount of bioactive compounds, and we found that the 1:1 ratio used for the purpose of this study was the most efficient. The most sensitive strains were Escherichia coli ATCC 25922 and Enterobacter clocae ATCC 13047. An average sensitivity was established in the case of strains Salmonella typhimurium ATCC 14028 and Staphylococcus aureus ATCC 29213, while Klepsiella pneumoniae ATCC 13833 and Yersinia enterocolitica ATCC 9610 strains had a very low sensitivity to these extracts. The results obtained recommend using Hibiscus sabdariffa strains to treat conditions caused by the strains under study as natural remedies, but not as much in the case of conditions generated by species such as Klepsiella pneumoniae ATCC 13833 and Yersinia enterocolitica ATCC 9610.

\section{REFERENCES}

1. Afolabi, O. C., Ogunsola, F. T., \& Coker, A. O. (2008). Susceptibility of cariogenic Streptococcus mutans to extracts of Garcinia kola, Hibiscus sabdariffa, and Solanum americanum. The West African Journal of Medicine, 27(4), 230-233.

2. Alarcon-Alonso, J., Zamilpa, A., Aguilar, F. A., HerreraRuiz, M., Tortoriello, J., \&Jimenez-Ferrer, E. (2012). Pharmacological characterization of the diureticeffect of Hibiscus sabdariffa Linn (Malvaceae) extract. Journal of Ethnopharmacology, 139(3), 751-756.

3. Beltran-Debon, R., Alonso-Villaverde, C., Aragones, G., Rodriguez-Medina, I., Rull, A., Micol, V., et al. (2010). The aqueous extract of Hibiscus sabdariffa calices

$\begin{array}{ll}2,87 \pm 0,01 & 2,99 \pm 0,01 \\ 1,41 \pm 0,01 & 1,81 \pm 0,01 \\ 0,31 \pm 0,01 & 0,61 \pm 0,01\end{array}$

$1,47 \pm 0,01$

$-$

$-$

modulates theproduction of monocyte chemoattractant protein-1 in humans. Phytomedicine, 17(3-4), 186-191.

4. Chao, C. Y., \& Yin, M. C. (2009). Antibacterial effects of roselle calyx extracts and protocatechuic acid in ground beef and apple juice. Foodborne Pathogens and Disease, 6(2), 201-206.

5. Da-Costa-Rocha I., Bonnlaender B., Sievers H, Pischel I, Heinrich M., (2014), Hibiscus sabdariffa L. - A phytochemical and pharmacological review, Food Chemistry 165, 424-443

6. Dickel, M. L., Rates, S. M., \& Ritter, M. R. (2007). Plants popularly used for loosing weight purposes in Porto Alegre, South Brazil. Journal of Ethnopharmacology, 109(1), 60-71.

7. Frank, T., Netzel, G., Kammerer, D. R., Carle, R., Kler, A., Kriesl, E., et al. (2012). Consumption of Hibiscus sabdariffa L. aqueous extract and its impact on systemic antioxidant potential in healthy subjects. Journal of the Science of Food and Agriculture, 92(10), 2207-2218.

8. Fullerton, M., Khatiwada, J., Johnson, J. U., Davis, S., \& Williams, L. L. (2011). Determination of antimicrobial activity of sorrel (Hibiscus sabdariffa) on Escherichia coli O157:H7 isolated from food, veterinary, and clinical samples. Journal of Medicinal Food, 14(9), 950-956.

9. Gaya, I. B., Mohammad, O. M. A., Suleiman, A. M., Maje, M. I., \& Adekunle, A. B.(2009). toxicological and lactogenic studies on the seeds of Hibiscus sabdariffa Linn (Malvaceae) extract on serum prolactin levels of albino wistar rats. The Internet Journal of Endocrinology, 5(2).

10. Gosain, S., Ircchiaya, R., Sharma, P. C., Thareja, S., Kalra, A., Deep, A., et al. (2010). Hypolipidemic effect of ethanolic extract from the leaves of Hibiscus sabdariffa L. in hyperlipidemic rats. Acta Poloniae Pharmaceutica, 67(2), 179-184.

11. Ismail, A., Ikram, E. H. K., \& Nazri, H. S. M. (2008). Roselle (Hibiscus sabdariffa L.) seeds nutritional composition protein quality and health benefits. Food, 2(1), 1-16.

12. Kumar, L., Dutt, D., \& Bharti, A. (2013). Delignification of Phragmites Karka - A wetland grass - by soda pulping process. BioResources, 8(3), 3426-3437.

13. Lin, H. H., Chan, K. C., Sheu, J. Y., Hsuan, S. W., Wang, C. J., \& Cheng, J. H. (2012). Hibiscus sabdariffa leaf induces apoptosis of human prostate cancer cells in vitro and in vivo. Food Chemistry, 132(2), 880-891.

14. Mohamed, B. B., Sulaiman, A. A., \& Dahab, A. A. (2012). Roselle (Hibiscus sabdariffa L.) in Sudan, cultivation and their uses. Bulletin of Environment, Pharmacology and Life Sciences, 1(6), 48-54.

15. Okoro, E. C. (2007). Production of red wine from roselle (Hibiscus sabdariffa) and pawpaw (Carica papaya) using palm-wine yeast (Saccharomyces cerevisiae). Nigerian 33 Food Journal, 25(2), 158-164. 
16. Peng, C. H., Chyau, C. C., Chan, K. C., Chan, T. H., Wang, C. J., \& Huang, C. N. (2011). Hibiscus sabdariffa polyphenolic extract inhibits hyperglycemia, hyperlipidemia, and glycation-oxidative stress while improving insulin resistance. Journal of Agricultural and Food Chemistry, 59(18), 9901-9909.

17. Plotto, A. (2004). Hibiscus: post-production management for improved market access. In: Food and Agriculture Organization of the UN (FAO).

18. Wang, C. J., Wang, J. M., Lin, W. L., Chu, C. Y., Chou, F. P., \& Tseng, T. H. (2000). Protective effect of Hibiscus anthocyanins against tert-butyl hydroperoxideinduced hepatic toxicity in rats. Food and Chemical Toxicology, 38(5), 411-416.

19. Wang, S. C., Lee, S. F., Wang, C. J., Lee, C. H., Lee, W. C., \& Lee, H. J. (2011). Aqueousextract from Hibiscus sabdariffa Linnaeus ameliorate diabetic nephropathy via regulating oxidative status and $\mathrm{Akt} / \mathrm{Bad} / 14-3-3$ gamma in an experimental animal model. Evidence-Based Complementary and Alternative Medicine, 2011,1-9.

20. Williamson, E. M., Driver, S. B., \& Baxter, K. (2013). Stockley's herbal medicines interactions: a guide to the interactions of herbal medicines, dietary supplements and nutraceuticals with conventional medicines. London: Pharmaceutical Press.

21. Yang, M. Y., Peng, C. H., Chan, K. C., Yang, Y. S., Huang, C. N., \& Wang, C. J. (2010). The hypolipidemic effect of Hibiscus sabdariffa polyphenols via inhibiting lipogenesis and promoting hepatic lipid clearance. Journal of Agricultural and Food Chemistry, 58(2), 850-859. 